\title{
Contact Stress Analysis for Gears of Different Helix Angle Using Finite Element Method
}

\author{
Santosh Patil ${ }^{1, \text { a }}$, Saravanan Karuppanan ${ }^{1}$ Ivana Atanasovska $^{2}$ Azmi A. Wahab ${ }^{1}$ and M. R. Lias ${ }^{1}$ \\ ${ }^{1}$ Department of Mechanical Engineering, Universiti Teknologi PETRONAS, Bandar Seri Iskandar, \\ 31750 Tronoh, Perak, Malaysia. \\ ${ }^{2}$ Institute Kirilo Savic, Belgrade, Serbia.
}

\begin{abstract}
The gear contact stress problem has been a great point of interest for many years, but still an extensive research is required to understand the various parameters affecting this stress. Among such parameters, helix angle is one which has played a crucial role in variation of contact stress. Numerous studies have been carried out on spur gear for contact stress variation. Hence, the present work is an attempt to study the contact stresses among the helical gear pairs, under static conditions, by using a 3D finite element method. The helical gear pairs on which the analysis is carried are $0,5,15,25$ degree helical gear sets. The Lagrange multiplier algorithm has been used between the contacting pairs to determine the stresses. The helical gear contact stress is evaluated using FE model and results have also been found at different coefficient of friction, varying from 0.0 to 0.3 . The FE results have been further compared with the analytical calculations. The analytical calculations are based upon Hertz and AGMA equations, which are modified to include helix angle. The commercial finite element software was used in the study and it was shown that this approach can be applied to gear design efficiently. The contact stress results have shown a decreasing trend, with increase in helix angle.
\end{abstract}

\section{Introduction}

Many studies on the gear contact stress analysis have been made by researchers and numerous works have been reported in technical literature [1-5]. The classical approch to problem evaluating contact stresses is Hertz theory of contact between two cylinders (line contact), which is suitable for spur gear pairs. This theory cannot be directly applied for the calculations of contact stress of helical gears pairs and require certain correction which have been shown in the later section. Helical gears differ from spur gears both in geometry and working behavior. Spur gears commonly have a contact line axially aligned and the load is distributed evenly across the width of the gear tooth. However, it is not the case for helical gears. The difference in contact lines is shown in Figure 1.

\footnotetext{
${ }^{a}$ Corresponding author: santosh045@gmail.com
} 


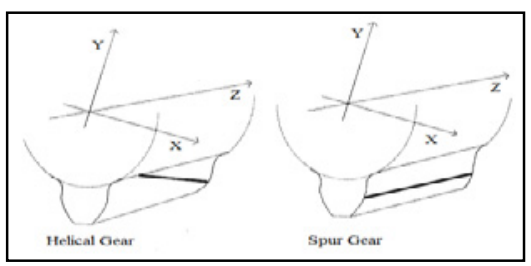

Figure 1. Line of contact along helical and spur gear

Vijayrangan et al. [1] studied the contact stress of a pair of mating spur gears, under static conditions, by using $2 \mathrm{D}$ FEM and Lagrangian multiplier technique. The results of the literature show a $5 \%$ increase in static contact stress when the friction coefficient is increased from 0.0 to 0.3 . Rao et al. [2] carried out root stress analysis on helical gear teeth using finite element method (FEM) and their work explains the effect of helix angle and face width and also the combined effect of both on maximum root stress. It was observed from the results that there is a slight variation in the maximum root stress values with the increase in helix angle for larger face widths. For smaller face widths, the maximum root stresses increase with increasing helix angle which agrees with previous literature for the range of helix angles between 15 and 35 degree. Muraro et al. [3] studied the influence of contact stress distribution and wear along the spur gear tooth contact. Similarly, few other authors have studied and found the stress variation along the contact of any mating gear [4,5].

The present work aims on the determination of contact stress for different sets of helical gears by $3 \mathrm{D}$ FEM using Lagrange multiplier algorithm. The helical gear pairs on which the analysis is carried out are $0,5,15,25$ degree helical gear sets. The results of the finite element analysis are validated using analytical calculations.

\section{Helical Gear Contact Stress Calculations}

In the case of spur gears with contact ratio less than 2 , the theoretical length of tooth contact is $1.0 \mathrm{~b}$ ( $\mathrm{b}$ is the length of contact). With helical gears, the length of contact per tooth is $\mathrm{b} / \cos \psi(\psi$ is helix angle) and the helical action causes the total length of tooth contact to be approximately $\mathrm{b} / \cos \psi$ times the contact ratio (CR) at all times. The AGMA recommends that $95 \%$ of this value be taken as the length of contact when computing contact stress. The contact stress equation is given as [6];

$$
\sigma_{H}=C_{p} \sqrt{\frac{F_{t}}{b d I}\left(\frac{\cos \psi}{0.95 C R}\right) K_{v} K_{o}\left(0.93 K_{m}\right)}
$$

where, $F_{t}$ is the transverse load, $\mathrm{b}$ is the length of contact, $\mathrm{d}$ is the pitch diameter of pinion/gear. Elastic coefficient factor $C_{p}$ is given as;

$$
C_{p}=0.564 \sqrt{\frac{1}{\frac{1-\mu_{1}^{2}}{E_{1}}+\frac{1-\mu_{2}^{2}}{E_{2}}}}
$$

where, E and $\mu$ are the Young's modulus and Poisson's ratio. Suffix 1 is for pinion and 2 is for gear. The geometry factor $I$ is given by:

$$
I=\frac{\sin \varphi \cos \varphi}{2} \frac{i}{i+1}
$$

where the speed ratio $\mathrm{i}=n_{1} / n_{2}=\mathrm{d}_{2} / \mathrm{d}_{1}$ and $\varphi$ is the transverse pressure angle. The contact ratio is given by:

$$
C R=\left(\frac{\sqrt{\left(r_{1}+a\right)^{2}-r_{b 1}^{2}}+\sqrt{\left(r_{1}+a\right)^{2}-r_{b 2}^{2}}-\left(r_{1}+r_{2}\right) \sin \varphi}{\pi m \cos \varphi}\right)
$$


where $r$ is the pitch circle radius, $r_{b}$ is the base circle radius, suffix 1 is for pinion and 2 is for gear, $a$ is the addendum, $\varphi$ is the transverse pressure angle. Velocity factor $\mathrm{K}_{\mathrm{v}}$ is calculated from equation 5 .

$$
K_{v}=\left[\frac{78+(200 \mathrm{~V})^{0.5}}{78}\right]^{0.5}
$$

$\mathrm{K}_{\mathrm{o}}$ is the overload factor which reflects the degree of non-uniformity of driving and load torques. $\mathrm{K}_{\mathrm{m}}$ is the load distribution factor which accounts for non-uniform spread of the load across the face width. It depends on the accuracy of mounting, bearings, shaft deflection and accuracy of gears. Thus, using the above theory contact stress will be calculated and FEA results will be verified.

\section{Finite Element Modeling of Gears}

The finite element models have been prepared for four sets of gear pairs. They are spur, $5 \mathrm{deg}$., 15 deg., and 25 deg. helical gear pairs. The specifications of these four gear sets have been represented in Table 1. The involute of the standard gear profile is been created using a macro which is generated in ANSYS APDL. The involute standard gear profile is copied three times to create a three-tooth segment of pinion and similarly that of gear. Further, they are brought together to form a meshed model. The gear pair volumes are discretized (meshed) using SOLID185 [7], a 3D element type suitable for determining the deformations, stress and strain with an appropriate utilization of time and computer resources. The contact between the gear pairs has been modelled using CONTA 174 and TARGE 170 element types [7]. The Lagrange multiplier algorithm has been used between the contacting pairs to determine the stresses. The meshed model of sample $5 \mathrm{deg}$. helical gear pair along with their boundary conditions is represented in Figure 2. The FE model is prepared such that it closely matches the real gear sets, and also as defined in the literature $[1,2,5]$.

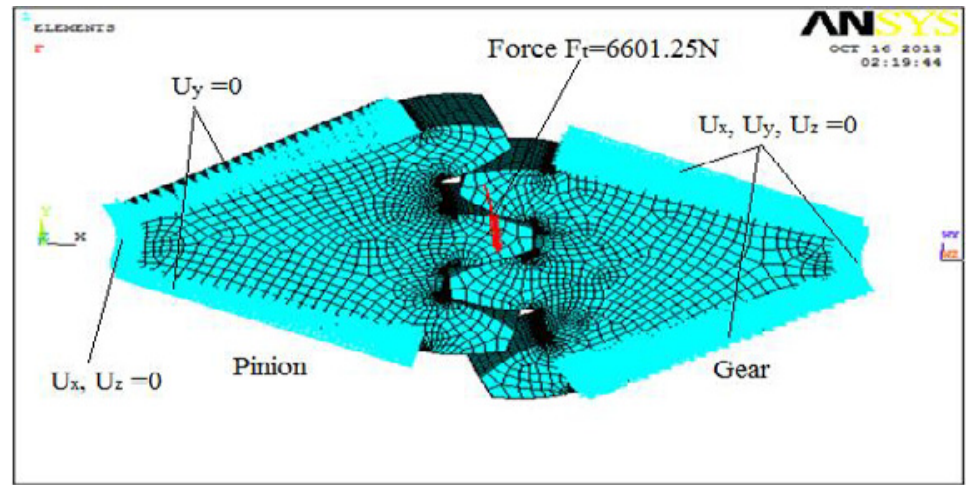

Figure 2. Sample meshed model of 5 degree helical gear set

\section{Results and Discussion}

In this study, finite element stress analysis was performed to investigate the effect of helix angle on contact stresses of gears. The results of contact stress for different helical gear sets have been summarized in Table 2. The analytical calculations done using the equations mentioned in second section is summarized along with the FE results in Table 2. It was observed that the decrease of stresses for small helix angle is less. For larger (15 to 25 degree) helix angle, the stress variation is between 7 to $8 \%$. The total drop of stresses for the change of helix angle from 0 to 25 degree is $11 \%$. Whereas FE results show a total drop of stresses by $17 \%$ with the increase of helix angle from 0 to 25 degree. The sample stress distribution results over a tooth flank for different helical gear sets has been represented in Figure 3 for $\mu=0.3$. 
Table 1. Gear design parameters

\begin{tabular}{|c|c|c|c|c|c|c|c|c|}
\hline \multirow[b]{2}{*}{ Parameter } & \multicolumn{2}{|c|}{ Spur Gear } & \multicolumn{2}{|c|}{5 deg. Helix Gear } & \multicolumn{2}{|c|}{15 deg. Helix Gear } & \multicolumn{2}{|c|}{25 deg. Helix Gear } \\
\hline & Pinio & Gear & Pinion & Gear & Pinion & Gear & Pinion & Gear \\
\hline No. of Teeth & 20 & 20 & 20 & 20 & 20 & 20 & 20 & 20 \\
\hline Normal Module & 4.5 & 4.5 & 4.5 & 4.5 & 4.5 & 4.5 & 4.5 & 4.5 \\
\hline $\begin{array}{l}\text { Normal } \\
\text { Pressure } \\
\text { Angle(deg.) }\end{array}$ & 20 & 20 & 20 & 20 & 20 & 20 & 20 & 20 \\
\hline $\begin{array}{l}\text { Helix angle } \\
\text { (deg.) }\end{array}$ & 0 & 0 & 5 & 5 & 15 & 15 & 25 & 25 \\
\hline $\begin{array}{l}\text { Pitch Diameter } \\
(\mathrm{mm})\end{array}$ & 91.5 & 91.5 & 91.84 & 91.84 & 94.72 & 94.72 & 100.95 & 100.95 \\
\hline $\begin{array}{l}\text { Face Width } \\
(\mathrm{mm})\end{array}$ & 20 & 20 & 20 & 20 & 20 & 20 & 20 & 20 \\
\hline $\begin{array}{l}\text { Center Distance } \\
(\mathrm{mm})\end{array}$ & \multicolumn{2}{|c|}{91.5} & \multicolumn{2}{|c|}{91.84} & \multicolumn{2}{|c|}{94.72} & \multicolumn{2}{|c|}{100.95} \\
\hline Contact Ratio & \multicolumn{2}{|c|}{1.556} & \multicolumn{2}{|c|}{1.54} & \multicolumn{2}{|c|}{1.525} & \multicolumn{2}{|c|}{1.51} \\
\hline Torque $(\mathrm{Nm})$ & \multicolumn{8}{|c|}{302} \\
\hline Speed (rpm) & \multicolumn{8}{|c|}{1000} \\
\hline $\begin{array}{l}\text { Young's } \\
\text { Modulus (GPa) }\end{array}$ & \multicolumn{8}{|c|}{210} \\
\hline Poisson's Ratio & \multicolumn{8}{|c|}{0.3} \\
\hline
\end{tabular}

From the Figure 4 it was observed that the maximum contact stress decreases with respect to helix angle. The results have been plotted for different frictional coefficients. The contact stress decreases with the increase in helix angle for a particular constant coefficient of friction value. The analytical calculations have been plotted in the same graph and they also show a similar pattern as that of FE results. FE models were found to be compatible in evaluating contact stress in helical gears. The results also show an increase of stresses with the increase in coefficient of friction.
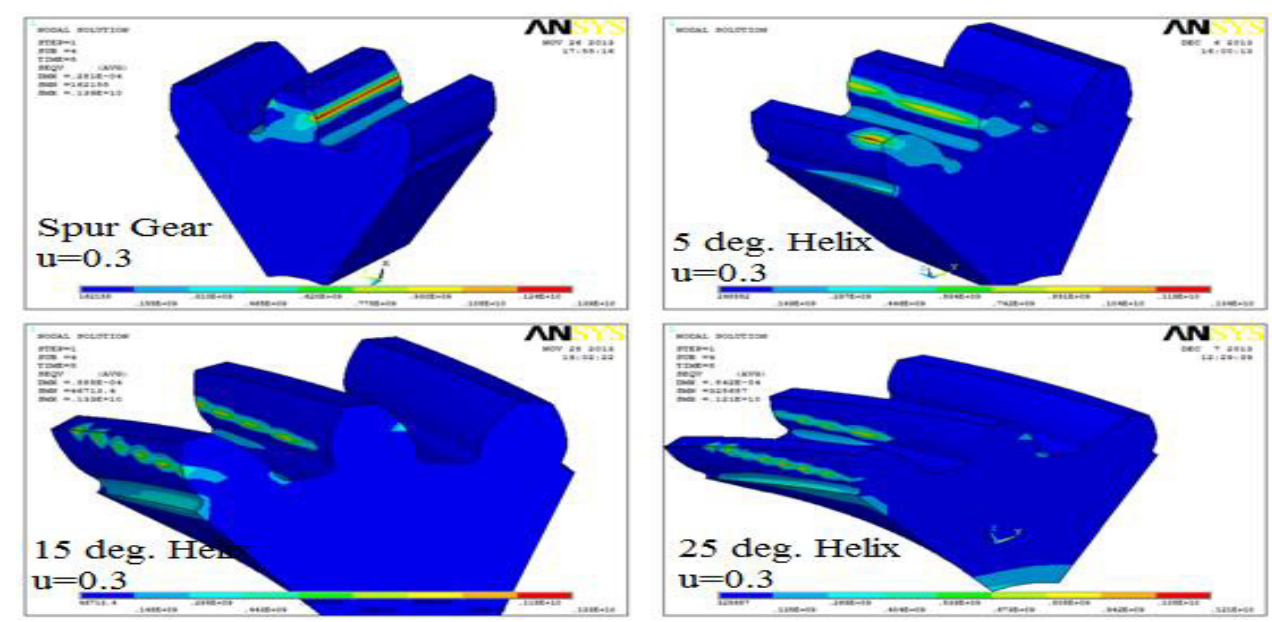

Figure 3. Maximum contact stress distribution for different helical gear sets 
Table 2. Contact stresses for different helix angles

\begin{tabular}{|c|c|c|c|c|c|c|}
\hline & \multirow{2}{*}{$\begin{array}{c}\text { Helix } \\
\text { angle }\end{array}$} & \multicolumn{4}{|c|}{ Maximum Contact Stress MPa } & \multirow{2}{\text{Analytical}}{$\begin{array}{c}\text { Stress } \\
\text { Calculations } \\
\text { MPa ( } \boldsymbol{\mu}=\mathbf{0})\end{array}$} \\
\cline { 3 - 6 } & & $\boldsymbol{\mu = 0}$ & $\boldsymbol{\mu}=\mathbf{0 . 1}$ & $\boldsymbol{\mu}=\mathbf{0 . 2}$ & $\boldsymbol{\mu}=\mathbf{0 . 3}$ & 1208 \\
\hline 1 & 0 & 1240 & 1260 & 1310 & 1390 & 1199.6 \\
\hline 2 & 5 & 1190 & 1230 & 1270 & 1340 & 1163.4 \\
\hline 3 & 15 & 1090 & 1130 & 1210 & 1330 & 1071.4 \\
\hline 4 & 25 & 1020 & 1060 & 1130 & 1210 & \\
\hline
\end{tabular}

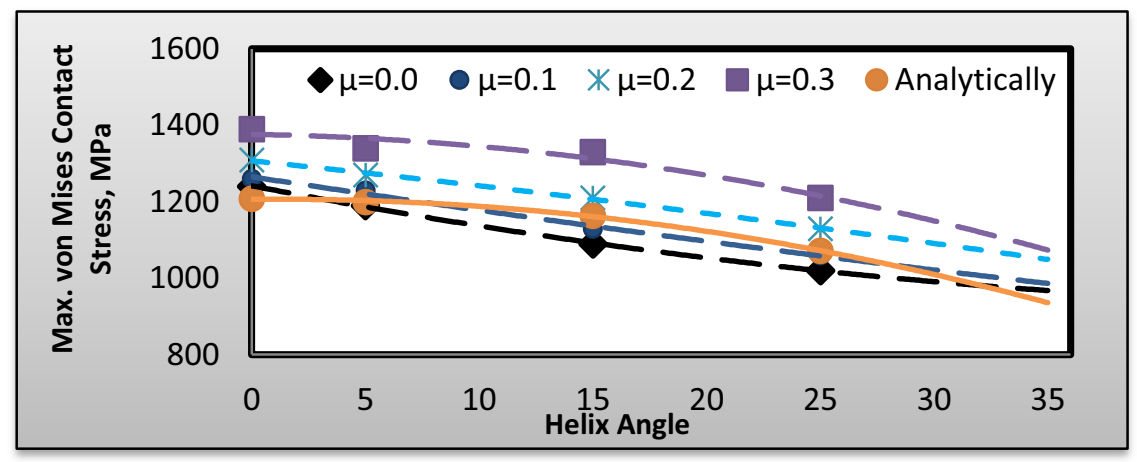

Figure 4. Maximum contact stress plot for different helix angle

\section{Conclusion}

The main conclusions obtained from the present work can be summarized as follows:-

1. The FE models of gear pairs are compatible in evaluating the contact stresses and the results obtained are in good agreement with analytical calculations

2. The effect of helix angle on contact stresses of gears has been shown and the contact stresses are inversely proportional with the helix angle. In the range of investigation, the maximum deviation in FE contact stress results compared to analytical results is $6 \%$, for the case of helix angle variation from 0 to 25 degree.

\section{Acknowledgements}

The authors would like to thank Universiti Teknologi PETRONAS for the facilities, system support and financial aid (URIF fund with cost center - 015 3AA B10).

\section{References}

1. S. Vijayarangan, N. Ganesan, Comput Struct. 51(6), 765-770 (1994)

2. C. R. M. Rao, G. Muthuveerappan, Comput Struct. 49(6), 1095-1106 (1993)

3. M. A. Muraro, F. Koda, Jr. U. Reisdorfer, C. H. Silva, J Brazil Soc of Mech Sciences and Engg. 34(2), 135-144 (2012)

4. I. Atanasovska, N.Stanojlovic, V. D. Dimitrijevic, and D. Momcilovic, Scientific Technical Review 59(1), 61-69 (2009)

5. S. Patil, S. Karuppanan, A. A. Wahab, Appl Mechanics and Materials 393, 403-408 (2013)

6. K. Gopinath, M. M. Mayuram, Machine Design II, IITM, Module 2, Lecture 11, 15-17. http://nptel.iitm.ac.in/courses/IIT-MADRAS/Machine_Design_II/pdf/2 11.pdf

7. ANSYS Release 14.0, Structural analysis guide, ANSYS Inc., Canonsburg, PA - 15317, USA 2013. 